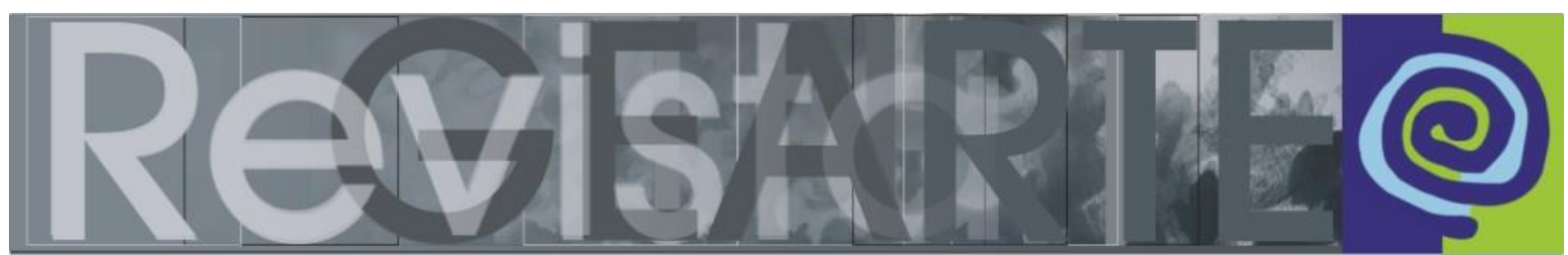

ISSN 2357-9854

\title{
O professor em foco na arte-educação contemporânea
}

\author{
Rosa lavelberg (Universidade de São Paulo — USP, São Paulo/SP, Brasil)
}

RESUMO - O professor em foco na arte-educação contemporânea - $O$ artigo trata da formação inicial e continuada de professores de Arte atuando na Educação Básica, enfatizando as questões didáticas. Destacam-se experiências de criação em oficinas e de aulas com os pares, da formação inicial. Do mesmo modo, ressalta-se a performance do professor de Arte na sala de aula, em formação continuada. No texto valorizou-se a aprendizagem colaborativa ou compartilhada entre os pares, conhecimento sobre arte, arte-educação contemporânea e sua história, formas de registro e reflexão sobre as práticas como instrumento de formação, transformação e atualização dos paradigmas dos professores na área de Arte.

\section{PALAVRAS CHAVE}

Formação de professores de Arte. Aprendizagem colaborativa. Registros, estágios e reflexões sobre as práticas didáticas

ABSTRACT - The teacher in focus in the contemporary art education - The article deals with initial and continuing education of Art teachers working in basic education, giving emphasis on the issues of Didactics. It highlights the creation of experiences in workshops and classes among peers at initial training. Likewise, it highlights the Art teacher performance in the classroom in continuing education. In the present text, it was appreciated collaborative or shared learning among peers, knowledge about art, contemporary art-education and its history, registration forms of and reflection on the practices as an instrument of formation, transformation and upgrading of the paradigms of teachers who work in the Art area.

\section{KEYWORDS}

Training Art teachers. Collaborative learning. Registrations, educational stages and reflections on teaching practices

\section{A formação inicial dos professores para o trabalho na área de Arte na Educação}

Básica é realizada nos cursos de Pedagogia, nos de Magistério de Nível Médio, nas Licenciaturas em Arte (para lecionar a partir do $6^{\circ}$ ano e no Ensino Médio), ou em Instituto Normal Superior ${ }^{1}$. Entretanto, dentro de cinco anos, a partir do $1^{\circ}$ ano, apenas

1 Em dezembro de 2010, o Conselho Nacional de Educação (CNE) aprovou a Resolução CEB no 7, fixando diretrizes para o Ensino Fundamental de nove anos. Entre outras questões relevantes, 0 documento estipula que, "[...] do $1^{\circ}$ ao $5^{\circ}$ ano do Ensino Fundamental, os componentes curriculares Educação Física e Arte poderão estar a cargo do professor de referência da turma, aquele com o qual os alunos permanecem a maior parte do período escolar, ou de professores licenciados nos respectivos componentes" (art. 31). Ou seja, tanto um pedagogo quanto um professor formado no magistério de nível médio estão autorizados a lecionar Arte e Educação Física. Contudo, esses profissionais não podem atuar com turmas do 6ํao em diante, nem no Ensino Médio (GIL, 2011). 
licenciados em uma linguagem específica entre as artes visuais, dança, música e teatro poderão ministrar aulas de arte.

Está em curso a discussão sobre a Base Nacional Curricular Comum que conterá propostas a partir das Diretrizes Curriculares Nacionais (2013). Mas sabe-se que, apesar das leis e dos documentos nacionais criados para orientar a escrita curricular terem como objetivo promover a área de Arte, ainda existem muitos entraves à concretização da proposta pós-modernista da arte-educação na maioria das escolas. Certamente, a formação dos professores de Arte - nas licenciaturas de artes visuais, dança, música e teatro -, será um passo à frente em relação àquilo que ora se apresenta nas escolas de Educação Básica.

Já os gestores e professores das creches e das pré-escolas poderão ser formados nos cursos de Pedagogia e Instituto Normal Superior. A formação dos gestores é fundamental para que compreendam o valor e as demandas da Didática da área de Arte para apoiar os professores no que se refere à formação continuada com relação a materiais, orientações didáticas, espaços adequados e interações com os demais profissionais das equipes escolares.

A formação continuada dos professores de Arte, depois das respectivas licenciaturas que passarão a ser requeridas, seguirá sendo importante, pois a atualização permanente diante dos avanços teóricos e práticos em cada uma das linguagens é uma necessidade. Tal aperfeiçoamento pode ocorrer em cursos presenciais ou à distância, de extensão, especialização ou em outras modalidades como encontros, palestras, seminários, simpósios, etc. É interessante que a formação continuada possa ser realizada de modo permanente nas próprias escolas ou redes escolares, reunindo professores, gestores e formadores em uma perspectiva de investigação e pesquisa sobre e nas práticas, sempre articuladas a bases teóricas.

Uma vertente atual da formação inicial e continuada para o ensino de Arte em muitos países e no Brasil consiste em considerar a história das tendências pedagógicas do ensino da área na educação escolar. No país e no exterior, é valorizado o conhecimento da história da arte-educação na formação dos arteeducadores, como se verifica nos textos de Barbosa e Sales (1990); Barbosa (1991, 
2001, 2003, 2014); Ferraz e Fusari (2009),entre outros. Acreditamos que as autoras citadas valorizam a consciência histórica da arte-educação como fonte de conhecimento e contextualização do presente. Nesse sentido, tais saberes orientam uma educação política diante da área de Arte.

A supervisão da prática dos participantes tem sido outra vertente da formação dos professores de Arte. Na formação inicial, essa supervisão incide sobre o estágio supervisionado que ocupa espaço privilegiado, e também sobre as aulas de História da Arte entre os pares. Na formação continuada, a tematização do trabalho dos professores em sala de aula tem sido o foco da orientação das práticas e da transformação dos paradigmas dos educadores, observando ações dos docentes no que se refere à promoção do conhecimento sobre arte e da criação artística dos alunos

Sendo assim, os registros das práticas dos professores na formação continuada por intermédio de diários, filmagens, filmagem em câmera lenta, relatos com documentação da prática dos trabalhos dos alunos, entre outras modalidades de apresentação do trabalho de sala de aula, revelam o paradigma de cada professor em formação. Além disso, a análise desses materiais, quando realizada em colaboração com os pares, sob orientação do formador, promove o avanço dos fundamentos didáticos do ensino e da aprendizagem em Arte. Esse professor, progressivamente, ganha segurança e valoriza o fato de expor, refletir e analisar sua prática à luz das contribuições dos colegas da mesma equipe, com os quais também estuda e aprofunda a articulação entre teoria e prática com a orientação do formador.

A mudança de paradigma, para níveis mais aperfeiçoados de domínio didático e sobre arte, tem como ponto de partida a prática e a reflexão real dos docentes em formação, que são instigados a refletir, mudar e ressignificar o papel do professor de Arte, por intermédio de intervenções colaborativas de formadores e colegas. Os seminários teóricos fazem par com as supervisões das práticas e ganham sentido, pois são a elas associados.

Valores fundamentais estão relacionados às propostas formativas da arteeducação contemporânea, e que operam em uma dupla vertente inclusiva, por um lado, com os alunos, enaltecendo o conhecimento sobre a produção social e histórica 
da arte em sua diversidade, base do patrimônio cultural, ampliando assim a possibilidade de participação na sociedade; por outro, na luta pela equidade com a inclusão do ensino da área nas escolas como direito de todos os cidadãos.

Do mesmo modo, a supervisão dos estágios dos alunos na formação inicial pode ser concretizada a partir de relatórios documentados e dos relatos das experiências vividas nas escolas, assim como a análise das aulas entre os graduandos serve para aprender a lecionar. Portanto, existem aproximações entre as estratégias da formação inicial e a praticada com arte-educadores nas escolas.

Assistir a colegas ministrar aulas, seja uma aula real ou simulada entre o grupo de professores em formação, e por eles ser visto, ativa aspectos procedimentais da formação que, sem tais práticas, não seriam incorporados. Planejar a própria prática apenas a partir da análise da anterior fica em desvantagem em relação à formação compartilhada, pois, no planejamento individual isolado da equipe, faltam bons modelos de referência de outros professores e as intervenções desses e dos formadores para reorientar a didática e fazer avançar paradigmas. Ser professor de Arte é pertencer a uma comunidade educativa que troca experiências, reconhece a necessidade de fundamentos e reconstrói permanentemente a reflexão e a ação didática.

\section{Aprender da história da formação dos arte-educadores}

A formação de professores de Arte, no momento moderno da arte-educação, seguia as demandas do papel a eles atribuído, tais como desenvolver uma relação amistosa com a criança em um viés psicológico, respeitando seu desenvolvimento artístico e estético em etapas evolutivas, valorizando os processos da livre expressão sem esperar que o aluno fizesse arte como um "pequeno adulto", ou que tivesse contato com a produção social e histórica da arte, com exceção feita de modo restrito aos adolescentes, em alguns casos. Objetivou-se no período, primordialmente, o desenvolvimento da criatividade, o que requeria sensibilidade a problemas, fluência, flexibilidade, originalidade, redefinição ou habilidade de rearranjo, análise ou habilidade de abstrair, capacidade de síntese e coerência de organização ( $C f$. 
LOWENFELD, 1961, p. 48), ou seja, de critérios mais ligados a condutas do que à aprendizagem de conteúdos do sistema da arte ou de sua produção social e histórica.

Arno Stern, artista e arte-educador modernista, que atuou na França, ao se referir aos professores de arte e aos artistas modernos assim se posicionou, situando a arte da criança:

\begin{abstract}
O educador não deve ser um artista; nem sequer é necessário que tenha uma cultura artística. Se conhece os problemas gerais da educação artística que estudamos aqui, o comportamento da criança que pinta Ihe será familiar. Se ficou na presença de pinturas infantis, sem nenhuma preparação, como simples aficionado, pode ser que tenha pensado que a arte infantil é uma "escola" da arte moderna. Mesmo sabendo como a criança cria e o que é, exatamente, o mundo plástico da criança, ainda pode ficar um pouco desorientado ante as primeiras "criações" que encontra no "ateliê", pois a criança se expressa em formas e cores muito violentas. A pintura infantil está muito perto da arte moderna, ou seja, muito longe daquela pintura na qual o espectador reconhecia todos os detalhes fotográficos. $\mathrm{O}$ artista é frequentemente atraído pela expressão plástica infantil e fica extasiado diante de suas audácias e investigações surpreendentes; comprova também, às vezes, que a criança encontrou, espontaneamente, aquilo que ele buscava penosamente (STERN, 1961, p. 22, tradução nossa).
\end{abstract}

Este pensamento sobre a formação do arte-educador modernista de Stern saiu da pauta das propostas formativas dos professores de Arte a partir dos anos 1980, quando ocorreu uma grande reorientação na qual se assimilou a necessidade de formação artística e didática desses educadores, em acordo com as demandas contemporâneas do ensino e da aprendizagem com reflexos no currículo de Arte das escolas. $\mathrm{Na}$ arte/educação moderna a docência era orientada à livre expressão e aconteceu em ateliês e em escolas experimentais progressistas que desenvolveram aulas de arte nas orientações contemporâneas. Hoje, a maioria das práticas ocorre em espaço escolar, pois Arte é disciplina obrigatória do currículo, mas segue sendo ensinada em outros locais, tais como: ateliês, museus, instituições culturais ou em oficinas de projetos sociais.

Como vimos, desde os anos 1980, a formação inicial e continuada dos professores de Arte tem como objetivo promover práticas articuladas a bases teóricas contemporâneas, que promovem a participação cultural e crítica na sociedade e a formação artística. As novas proposições foram desenvolvidas em diversos países e foram trazidas e concretizadas no Brasil por intermédio da Abordagem Triangular da Prof $^{a}$ Ana Mae Barbosa. Nos anos 1990, chegaram às escolas, de todo território 
nacional, os Parâmetros Curriculares Nacionais (PCN), elaborados em consonância com a LDB 9394/96. É interessante pensar que os alunos das creches e pré-escolas da época, hipoteticamente, vinte e cinco anos depois, poderiam ingressar no ensino superior com formação em arte, se tivessem cursado a Educação Básica nas orientações pós-modernas da Abordagem Triangular ou dos PCN, mas, infelizmente, não é o que se verifica entre os futuros professores nos cursos de formação inicial.

Antes da obrigatoriedade do ensino de Arte nos termos da última LDB, que visou à formação na área, quem prestava vestibular para cursos em que se pedia tal habilitação, como Arquitetura ou bacharelado e licenciatura em Artes Visuais, por exemplo, cumpria com a totalidade das demandas do exame em cursinhos de preparação para o vestibular ou aulas particulares, devido à defasagem entre o currículo das escolas e as provas de seleção, e isso segue sendo assim, devido ao difícil quadro da formação inicial dos professores da Educação Básica, que abordaremos a seguir.

Sabe-se que a aprendizagem dos alunos em Arte nas escolas de Educação Básica ainda não se realizou em sua totalidade. Tem-se um longo caminho pela frente e espera-se que a Base Nacional Curricular Comum, em andamento, mobilize discussões sobre a arte na educação escolar, impulsionando a formação de professores e políticas públicas de valorização da área e da docência, atuando na melhoria da escola e na qualidade de vida da comunidade de educadores, alunos e de seus familiares, pois o contexto do cotidiano desses protagonistas interfere, sobremaneira, na aprendizagem dos estudantes. Documentos e leis por si só não alcançam a melhoria do ensino em uma área do conhecimento. A complexidade do sistema educacional requer reorientação política vigorosa para que a educação em todas as áreas, incluindo a de Arte, possa se efetivar com equidade para todos os alunos.

O cenário atual da formação de professores de Arte é difícil e complexo e urge ser aperfeiçoado, pois ele nos mostra que, para além dos aspectos qualitativos da formação, os quantitativos não podem ser subestimados quando se pensa em um plano nacional de promoção do ensino na área. 
Como se pode verificar no Quadro I a seguir, referente ao Censo de 2012 sobre professores de Arte com formação na área em que atuam na Educação Básica, relativo ao Ensino Fundamental 2, nos demais segmentos, ainda é o professor regente quem ministra as aulas em grande parte das escolas.

Quadro I - Censo Escolar 2012, professor de arte com formação na área em que atua. Ensino Fundamental 2.

\begin{tabular}{|c|c|c|c|c|c|c|c|c|}
\hline & \multirow{2}{*}{$\begin{array}{c}\text { Total de } \\
\text { docentes } \\
\text { lecionan- } \\
\text { do a disci- } \\
\text { plina de } \\
\text { Artes }\end{array}$} & \multirow{2}{*}{$\begin{array}{c}\text { Total de } \\
\text { docentes } \\
\text { com } \\
\text { formação } \\
\text { em Artes }{ }^{1}\end{array}$} & \multicolumn{5}{|c|}{$\begin{array}{l}\text { Docentes por formação específica (o mesmo docente } \\
\text { pode ter mais de uma formação específica) }\end{array}$} & \multirow{2}{*}{$\begin{array}{c}\text { Docentes } \\
\text { com mais } \\
\text { de uma } \\
\text { formação } \\
\text { específica }\end{array}$} \\
\hline & & & $\begin{array}{c}\text { Bachare- } \\
\text { lado } \\
\text { interdiscipli } \\
\text { nar em } \\
\text { Artes }\end{array}$ & $\begin{array}{c}\text { Artes } \\
\text { Visuais }\end{array}$ & $\begin{array}{l}\text { Artes } \\
\text { Cênicas }{ }^{1}\end{array}$ & Dança $^{1}$ & Música' & \\
\hline Brasil & 536,488 & 29,195 & 19,04 & 8,377 & 406 & 122 & 1,435 & 185 \\
\hline Norte & 72,821 & 982 & 422 & 433 & 3 & 4 & 126 & 6 \\
\hline Rondônia & 5,357 & 26 & 18 & 3 & - & - & 5 & 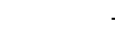 \\
\hline Acre & 4,965 & 38 & 9 & 20 & - & - & 10 & 1 \\
\hline Amazonas & 18,279 & 146 & 40 & 81 & - & 3 & 22 & 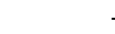 \\
\hline Roraima & 1,848 & 12 & 7 & 5 & - & - & - & 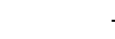 \\
\hline Pará & 31,481 & 529 & 228 & 218 & 2 & 1 & 84 & 4 \\
\hline Amapá & 3,855 & 210 & 112 & 99 & - & - & - & 1 \\
\hline Tocantins & 7,036 & 21 & 8 & 7 & 1 & - & 5 & 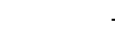 \\
\hline Nordeste & 210,908 & 2,113 & 1,263 & 509 & 83 & 38 & 241 & 21 \\
\hline Maranhão & 41,631 & 230 & 148 & 65 & 8 & 1 & 8 & 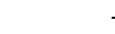 \\
\hline Piauí & 14,379 & 105 & 81 & 20 & 1 & 1 & 2 & 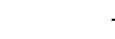 \\
\hline Ceará & 34,158 & 90 & 15 & 17 & 6 & 2 & 51 & 1 \\
\hline Rio Grande do Norte & 12,432 & 298 & 153 & 98 & 10 & 3 & 37 & 3 \\
\hline Paraíba & 13,755 & 254 & 168 & 65 & 9 & 1 & 16 & 5 \\
\hline Pernambuco & 40,037 & 205 & 104 & 67 & 2 & - & 35 & 3 \\
\hline Alagoas & 13,077 & 186 & 116 & 39 & 16 & 1 & 14 & 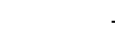 \\
\hline Sergipe & 9,036 & 74 & 28 & 38 & 4 & 1 & 3 & 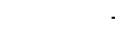 \\
\hline Bahia & 32,403 & 671 & 450 & 100 & 27 & 28 & 75 & 9 \\
\hline Sudeste & 148,2855 & 18,041 & 13,537 & 3,731 & 188 & 50 & 588 & 53 \\
\hline Minas Gerais & 55,956 & 1,47 & 1,008 & 326 & 25 & 6 & 115 & 10 \\
\hline Espírito Santo & 7,043 & 464 & 267 & 162 & 2 & 1 & 35 & 3 \\
\hline Rio de Janeiro & 21,637 & 3,176 & 1,052 & 1,605 & 128 & 26 & 383 & 18 \\
\hline São Paulo & 63,649 & 12,931 & 11,21 & 1,638 & 33 & 17 & 55 & 22 \\
\hline Sul & 60,352 & 6,202 & 2,924 & 2,926 & 91 & 27 & 316 & 82 \\
\hline Paraná & 19,818 & 2,428 & 1,209 & 1,075 & 35 & 8 & 131 & 30 \\
\hline Santa Catarina & 8,51 & 1,564 & 701 & 820 & 17 & 1 & 44 & 19 \\
\hline Rio Grande do Sul & 32,024 & 2,21 & 1,014 & 1,031 & 39 & 18 & 141 & 33 \\
\hline Centro-Oeste & 44,122 & 1,857 & 894 & 778 & 41 & 3 & 164 & 23 \\
\hline Mato Grosso do Sul & 3,564 & 502 & 124 & 365 & 1 & - & 14 & 2 \\
\hline Mato Grosso & 13,157 & 259 & 190 & 11 & - & - & 58 & - \\
\hline Goiás & 19,706 & 390 & 130 & 187 & 7 & 2 & 73 & 9 \\
\hline Distrito Federal & 7,695 & 706 & 450 & 215 & 33 & 1 & 19 & 12 \\
\hline
\end{tabular}

Em relação aos docentes com formação em arte no Ensino Fundamental 2,

[...] o total de docentes lecionando a disciplina de Artes (sic) é de 536.488, sendo que entre estes apenas 29.195 possuem formação em Artes 
(Licenciatura ou Bacharelado-L/B), assim distribuídos: 19.400 (bacharelado interdisciplinar em Artes); 8.377 (Artes Visuais - L/B); 406 (Artes Cênicas L/B); 122 (Dança L/B); 1435 (Música L/B) e temos ainda 185 docentes com mais de uma formação específica.

Aos dados acima se acrescem gritantes diferenças regionais. Dos 29.195 docentes com formação em Artes, 982 estão na região Norte; 2.133, na Nordeste; 18.041, na Sudeste; 6.202, na Sul; e 1.857, na Centro-Oeste.

Com base nesses dados, verifica-se que $94,7 \%$ dos professores que lecionam Arte no país não possuem formação em arte. Acreditamos, como muitos formadores, que além da formação inicial a escola precisa se constituir como um lugar de formação continuada dos professores de Arte, tanto para suprir as faltas de formação inicial como para garantir a atualização permanente (IAVELBERG, 2013, p. 53-54).

No Censo de 2013, houve um acréscimo: passou-se de 5,3\% a 7,7\% de professores com formação na área para o segmento do Ensino Fundamental 2, número ainda muito baixo diante da demanda das escolas e a complexidade que envolve a formação requerida para cumprir as orientações das novas Diretrizes Curriculares Nacionais da Educação Básica, DCNEB, (2013).

Quadro II - Censo Escolar 2013, professor de arte com formação na área em que atua. Ensino Fundamental 2 (Observatório PNE - 15, 2016).

Disciplina / Artes / Com licenciatura em artes anos finais Ensino Fundamental

\begin{tabular}{lrrrrrrr}
\hline & $\begin{array}{c}\text { Código } \\
\text { IBGE }\end{array}$ & 2011 (\%) & $\begin{array}{c}\text { 2011 } \\
\text { (absoluto) }\end{array}$ & 2012 (\%) & $\begin{array}{c}\mathbf{2 0 1 2} \\
\text { (absoluto) }\end{array}$ & $\mathbf{2 0 1 3}$ (\%) & \multicolumn{1}{c}{$\begin{array}{c}\mathbf{2 0 1 3} \\
\text { (absoluto) }\end{array}$} \\
\hline Brasil & $\mathbf{0}$ & $\mathbf{4 , 1}$ & $\mathbf{6 4 0 1 , 0}$ & $\mathbf{5 , 3}$ & $\mathbf{8 2 9 5 , 0}$ & $\mathbf{7 , 7}$ & $\mathbf{1 1 9 9 6 , 0}$ \\
Norte & 1 & 1,3 & 322,0 & 1,7 & 439,0 & 2,1 & 533,0 \\
Nordeste & 2 & 0,5 & 358,0 & 0,8 & 561,0 & 1,0 & 691,0 \\
Sudeste & 3 & 9,6 & 3197,0 & 11,9 & 4068,0 & 20,8 & 6917,0 \\
Sul & 4 & 12,1 & 2012,0 & 16,0 & 2664,0 & 19,3 & 3196,0 \\
Centro-Oeste & 5 & 5,0 & 512,0 & 5,5 & 563,0 & 6,4 & 659,0 \\
\hline
\end{tabular}

Em creches, Educação Infantil e Ensino Fundamental do $1^{\circ}$ ao $5^{\circ}$ ano, com algumas exceções, ainda é o professor regente quem ministra as aulas de Arte. Portanto, a formação precisa contemplar todas as linguagens, o que constitui um problema ao aprofundamento necessário em cada uma delas. A polivalência foi e segue sendo muito criticada na comunidade de arte-educadores porque é ineficaz, banaliza o ensino de Arte e está relacionada à Lei 5692/71, datada na época da ditadura militar, quando Arte foi concebida como atividade e não como área de conhecimento. Neste sentido, a LDBEN n 9394/96 deu à Arte o estatuto de área de conhecimento obrigatória, com conteúdos próprios para promover a formação artística 
e cultural dos alunos. A orientação dos documentos dos Parâmetros Curriculares Nacionais, produzidos no período, indicava que os professores não trabalhassem as linguagens da arte (artes visuais, dança, música e teatro) de modo polivalente, mas sim disciplinarmente e, por vezes, interdisciplinarmente, respeitando a natureza de cada linguagem. Frente ao Quadro I do Censo Escolar de 2012 sobre formação de professores de Arte, podemos verificar que a linguagem que requer mais formação de profissionais é Dança, seguida por Artes Cênicas e Música.

\section{Diretrizes Curriculares Nacionais da Educação Básica}

Em 2013, foram publicadas as Diretrizes Curriculares Nacionais da Educação Básica, referentes às suas três etapas: Educação Infantil: creche (de zero a três anos e 11 meses) e pré-escola (4 e 5 anos); Ensino Fundamental do $1^{\circ}$ ao $9^{\circ}$ ano e Ensino Médio (três anos de duração). Essas diretrizes tratam de normas obrigatórias para a Educação Básica, que visam orientar a elaboração de currículos em escolas e redes, especificando conteúdos mínimos, obrigatórios, que preservam a formação básica tendo como referência a LDBEN de 1996, além de definirem competências e diretrizes para uma base nacional comum e outra diversificada.

Arte no segmento do Ensino Fundamental de nove anos, no documento citado, está incluída como componente curricular obrigatório na área de conhecimento denominada "Linguagens", que abarca outros componentes: Língua Portuguesa; Língua Materna, para populações indígenas; Língua Estrangeira Moderna e Educação Física. Portanto, Arte figura, na realidade, como subcomponente da área de conhecimento Linguagens, o que significa um retrocesso em relação aos PCN, nos quais Arte era uma área de conhecimento como as demais, com conteúdos próprios dentro das orientações da arte-educação contemporânea da qual faz parte o conhecimento dos modos próprios à produção da arte na sociedade no que se refere a percurso de criação, modos de exibição e leitura da arte, incluindo os aspectos políticos, econômicos e sociais de fatura, distribuição e acesso aos bens culturais.

\section{Pesquisa, reflexão sistemática e a prática educativa de qualidade}

É preciso que os professores compreendam os benefícios da aprendizagem compartilhada para abrir suas práticas à tematização, crítica e visualização 
da necessidade de mudanças, mas também de sucessos e práticas modelares inspiradoras aos pares (IAVELBERG, 2013, p.189).

É fundamental que o professor conheça os autores de arte-educação, da arte e da educação, tanto quanto que ele saiba contextualizar esses textos na história das tendências pedagógicas, para poder se situar na contemporaneidade, consciente da origem e do percurso de transformação das ideias que regem a didática da área na atualidade.

Esse conhecimento corrobora a formação de um professor investigador, que sabe analisar as próprias práticas, que associa os documentos oficiais ao currículo da escola, que o elabora com os pares e pode modificá-lo ou adequá-lo ao contexto de trabalho, levando em consideração as especificidades deste.

A familiaridade com instrumentos de avaliação das aprendizagens e das práticas nas escolas pode ser incentivada na formação dos professores que têm a possibilidade de aprender a se responsabilizar por avaliar, analisando a prática, fruto das teorias em ação incidentes nas intenções, procedimentos e tomada de decisões de quem ensina. Ser avaliado, e avaliar de modo compartilhado com a participação de formadores, pares e gestores consiste hoje num dos aspectos da formação continuada e demanda a articulação entre teoria e prática.

Muitas são as modalidades de formação inicial e continuada na área de Arte. Alguns museus brasileiros a oferecem para professores por intermédio de cursos de História da Arte, oficinas de criação, materiais de apoio didático sobre o acervo ou mostra específica, projetos que levam obras e reproduções às escolas, palestras, visitas orientadas, recepção de alunos e professores de escolas ou da formação inicial, que aprendem nesta interlocução.

Os materiais de apoio didático elaborados nestas instituições, como ocorre com os livros didáticos de qualidade, podem ser usados com autonomia pelos professores e auxiliam na formação continuada. Os professores podem analisar esses materiais para compreender sobre seus conteúdos e a estrutura a eles subjacente, para que saibam selecioná-los com mais critérios e possam planejar atividades com autonomia, informados pelos exemplos bem estruturados que um material apresenta. Esses 
materiais também se aplicam à formação inicial como recurso de pesquisa e fonte de estudo para dar conta de ministrar aulas de Arte.

A internet permite a pesquisa em sites de museus de arte ou de artistas brasileiros e estrangeiros, passando assim a ser um meio que colabora com a formação inicial e continuada no planejamento de aulas. Apesar de poucos sites de museus estrangeiros com materiais e textos em língua portuguesa, muitos deles são confiáveis, podendo ser aproveitados como fonte de estudo e informação.

É importante que não haja conflito entre a didática da formação e a da sala de aula, pois os mesmos princípios didáticos devem nortear as duas situações de ensino e aprendizagem. Nesse sentido, é necessário trabalhar com os conhecimentos prévios dos educadores para promover avanços em níveis mais complexos de saber. É relevante que se possa verificar se os professores em formação estão aprendendo de maneira criadora e autoral, do mesmo modo como queremos que aconteça com os alunos por eles ensinados nas escolas.

Os estereótipos e vícios arraigados nas práticas educativas podem ser desconstruídos de forma mais eficaz se os professores passarem por uma experiência profunda e extensa em relação ao conhecer e ao fazer arte. Uma das finalidades da formação dos professores de Arte é que eles incluam arte em suas vidas, pois assim poderão promovê-la na dos estudantes.

Acreditamos que os professores em formação precisam valorizar a arte na própria formação a partir de uma experiência em movimentos alternados, tal qual ocorrerá na aprendizagem artística dos alunos. Tal experiência consiste em haver alternância entre as consignas do professor e as de livre decisão do aluno. Isso faz com que o estudante crie trabalhos autorais e cultivados, ou seja, influenciados pelas culturas advindas da produção social e histórica da arte, pois os atos de criação a partir de enunciados que o aluno faz a si mesmo, nesse contexto de ações alternadas, aproximam suas criações das que ocorrem nas práticas sociais, daqueles que fazem e pensam sobre arte na sociedade (Cf. IAVELBERG, 2010, p. 65). 
Nas ações de formação inicial e continuada, é necessário que os professores aprendam e aprofundem as teorias sobre a gênese do desenvolvimento do fazer artístico e da compreensão estética (saber ler trabalhos de arte) de crianças e jovens, porque tais fundamentos teóricos, advindos de pesquisas, pautam a prática do professor em sala de aula. A ponte entre pesquisa, reflexão sistematizada e prática educativa pode promover o ensino na área de Arte.

A observação de trabalhos infantis, a tematização de sua evolução histórica e sua diversidade nas culturas, assim como a atualidade tecnológica que eles podem alcançar, precisam compor os estudos teóricos e as tematizações das práticas dos professores em formação.

Por fim, frente às proposições do ensino de Arte na contemporaneidade, se requer do professor criar ao aprender nos momentos de formação inicial ou continuada, cabendo aos formadores construir uma identificação com as proposições teóricas contemporâneas que norteiam o ensino e a aprendizagem. Hoje é fundamental aos professores a compreensão dos processos de criação dos alunos, a formação nos âmbitos do fazer e do conhecer arte, bem como dos procedimentos didáticos. Desse modo, o portfólio de cada professor em formação inicial ou continuada consiste num objeto importante, que conta a história de um processo formativo específico. Dele podem constar produções como: um conjunto de trabalhos artísticos pessoais, os escritos produzidos, os registros de produções coletivas, um diário com reflexões sobre o próprio processo de criação e formação, pontuando alcances e faltas, textos de autoavaliação. Estes são, entre outros, itens representativos das aprendizagens dos professores em formação, que podem ser compartilhados com seus pares.

A teoria e a prática são igualmente importantes na formação do professor de Arte. A teoria por constituir um conjunto de bases coerentes entre si, de ordem filosófica, epistemológica, psicopedagógica, didática, artística e histórica, que podem formar um profissional que se quer autoral, investigador e criador de seu trabalho. Convém ressaltar que a teoria em associação com a prática tem força emancipatória, por desenvolver intuição, imaginação, percepção direta dos fenômenos, leitura da arte e sua fatura, ou seja, tal articulação pode aperfeiçoar competências e conhecimentos 
ao alinhá-los em um sistema coerente e em permanente transformação, dado que as teorias e as práticas se transformam no tempo e nos diferentes contextos nos quais se dá a educação. De qualquer modo, na contemporaneidade, são as teorias e as práticas já alcançadas, selecionadas e eleitas pelos professores em formação que fazem interlocução com as bases teóricas apresentadas e os procedimentos práticos mediados pelos formadores, para que, ao longo e ao fim do processo, aqueles que ensinam Arte valorizem a articulação entre teoria e prática.

\section{Referências}

BARBOSA, Ana Mae. A imagem no ensino da arte. São Paulo: Perspectiva, 1991.

BARBOSA, Ana Mae. John Dewey e o ensino da arte no Brasil. 3. ed. rev. e aum. São Paulo: Cortez, 2001.

BARBOSA, Ana Mae. Arte no Brasil: do modernismo ao pós-modernismo. Revista Digital Art \&, Ano I, n. 0, out. 2003. Disponível em: <http://www.revista.art.br/site-numero-00/artigos.htm>. Acesso em: jul. 2014.

BARBOSA, Ana Mae. O Teachers College e sua influência na modernização da educação do Brasil. Revista Gearte, v. 1, n. 1, abril/2014, ISSN 2357-9854. Disponível em: <http://seer.ufrgs.br/index.php/gearte/article/view/46544/31235>. Acesso em: 1을 2014.

BARBOSA, Ana Mae; SALES, Heloisa Margarido. (Orgs.). O ensino da arte e sua história. São Paulo: MAC/USP, 1990.

FERRAZ, Heloísa C. de T.; FUSARI, Maria F. de Rezende e. Metodologia do ensino da arte. 2. ed. rev. ampl. São Paulo: Cortez, 2009.

IAVELBERG, Rosa. O pêndulo didático. In: SILVA, Dilma de Melo (Org.).Interdisciplinaridade, transdisciplinaridade no estudo e pesquisa da arte e cultura. São Paulo: Terceira Margem, 2010, p. 59-65.

IAVELBERG, Rosa. O ensino de arte na educação no Brasil. Revistausp, n. 100, 2013. Edição comemorativa dos 25 anos, Especial Educação, São Paulo, Imprensa Oficial, p. 47-56.

IAVELBERG, Rosa. A formação de professores de arte: alcances e ilusões. In: CARVALHO, Anna Maria Pessoa de. Formação de professores: múltiplos enfoques.São Paulo: FEUSP/SARANDI/FAFE, 2013, p. 181-192.

LOWENFELD, Viktor; BRITTAIN, W.L. Desarrollo de la capacidad creadora. v. 1 e 2. Buenos Aires: Kapelusz; 1961.

STERN, Arno. Aspectos e técnica de la pintura infantil. Buenos Aires: Kapelusz,1961.

\section{Documentos Nacionais}

BRASIL. Ministério da Educação. Secretaria de Educação Básica. Secretaria de Educação Continuada, Alfabetização, Diversidade e Inclusão. Conselho Nacional de Educação. Diretrizes curriculares nacionais da educação básica. Brasília: MEC/SEB/DICEI, 2013.

Secretaria do Ensino Fundamental. Parâmetros curriculares nacionais: arte para o ensino fundamental ( $1^{\circ}$ e $2^{\circ}$ ciclos). Brasília: MEC/SEF, 1997.

Parâmetros Curriculares Nacionais: arte para o ensino fundamental ( $3^{\circ}$ e $4^{\circ}$ ciclos). Brasília: MEC/SEF, 1998. 
OBSERVATÓRIO DO PNE - 15. FORMAÇÃO DE PROFESSORES - Indicadores de meta. Disponível em:

$<$ http://www.observatoriodopne.org.br/metas-pne/15-formacaoprofessores/indicadores\#porcentagem-de-professores-do-ensino-medio-que-tem-licenciatura-na-areaem-que-atuam>. Acesso em: 3 abril. 2016.

\section{Rosa lavelberg}

Professora Livre-docente do Departamento de Metodologia de Ensino da Faculdade de Educação da Universidade de São Paulo. Autora dos livros: Para gostar de aprender arte: sala de aula e formação de professores, Artmed, 2003; O desenho cultivado da criança: práticas e formação de educadores. Porto Alegre: Zouk, 2006; Arslan Luciana \& lavelberg Rosa. Ensino de Arte. São Paulo: Thomson, 2006; Desenho na educação infantil. São Paulo: Melhoramentos, 2013. Líder com Carmen Aranha do Grupo de pesquisa Formação de Professores e Aprendizagem em Arte (CNPq).

E-mail: riavelberg@gmail.com

Currículo: http://lattes.cnpq.br/3612410780790990

Recebido em 5 de março 2016 Aceito em 10 de abril de 2016 